\title{
Using Post Course Assessments To InVOLVE INSTRUCTORS IN THE CONTINUOUS IMPROVEMENT PROCESS
}

\author{
Ivey, M., Dew S., Mandal M., Mohamed Y., Nychka J.A., Raboud D., Carey J.P., \\ University of Alberta, Faculty of Engineering, Edmonton, Alberta. \\ Jason.carey@ualberta.ca
}

\begin{abstract}
Continuous improvement is a critical aspect of engineering program development and accreditation. Instructors are important stakeholders who can provide valuable feedback with regards to courses and curriculum; however, obtaining this information can be problematic. Here we present a post course assessment system (PCAS) that enables all instructors to provide timely and specific feedback about their courses as well as pause to reflect on the pedagogical successes and challenges they have faced over the course of a semester. The PCAS also serves a number of program specific uses (triggers, graduate attributes, consistency). The system has been very successful if providing course-based information and, taken in aggregate, program-based insight. The system continues to be adapted but is a good model of instructor engagement and feedback mechanism.
\end{abstract}

Keywords: Post course assessment, graduate attributes, instructor involvement, action triggers, continuous improvement.

\section{INTRODUCTION}

Our programs aim to continuously adapt to meet the needs of the various stakeholders of our undergraduate students' education and training. As with most, if not all Canadian Universities, courses and instructors are generally evaluated by students through the universal student rating of instruction (USRI), from which debatable data can be obtained [1]. In addition, the translation of USRI feedback to program and course improvements is quite limited.

Continuous improvement is a critical aspect of engineering program development, and is also an integral aspect of the Canadian Engineering Accreditation Board (CEAB) accreditation review [2]. A number of different approaches are used by programs, engineering and others, to adapt their programs to the changing landscape [3-7].

There are a number of valuable stakeholders that are regularly suggested and consulted in an attempt to improve our engineering programs [2]. Curriculum committee members, students, pedagogy experts, industry, non- engineering experts, alumni, professional regulating organizations (e.g. Association of Professional Engineers and Geoscientists of Alberta), learned society members and many others typically make up the list of stakeholders invited to provide insight to programs. However, often over-looked and likely most important of all stakeholders, are the individual instructors who can provide valuable feedback with regards to courses and curriculum [8-9]. It is our experience that instructor feedback is vital but seldom forthcoming. This apparent reluctance is especially so in large multi-instructor courses; courses with new instructors unsure if they could/should provide feedback as much as more senior professors; or courses with resource constraints.

In the Faculty of Engineering at the University of Alberta, it is our philosophy that only by obtaining information from individual professors can we truly understand the on-going issues, concerns, and inconsistencies; recognize successes; determine best practices; and ensure that our programs remain relevant to all stakeholders involved.

However, obtaining this information has been historically problematic. Attempts to bring together faculty members to discuss important pedagogical aspects of our programs, such as curriculum, course content, learning outcomes, and graduate attributes, can often be confronted by busy academic schedules and commitments. It can also be seen with much cynicism and apathy as all too often the impact of program discussions is not seen at the course level.

To circumvent these issues, and put our philosophy to practice, the Faculty of Engineering academic planning committee (APC) developed a post course assessment system (PCAS) between 2014 and 2016 that requires all instructors to provide timely and specific feedback about their courses as well as pause to reflect on the pedagogical successes and challenges they have faced over the course of a semester. The PCAS provides a formal mechanism to bring instructors into the course improvement process. The PCAS forms are used by an instructor for their own course and for program administrators as oversight for all courses in their program. As a tool for continuous program improvement, the PCAS has built-in triggers that give 
program curriculum committees and undergraduate program associate chairs an indication of current curriculum issues, student preparedness, graduate attributes, and learning outcomes among other valuable data. The review of the PCAS data provides a greater level of assurance that appropriate curriculum is being taught in courses, as laid out in our curriculum maps. It also allows instructors the opportunity to provide input on where graduate attributes are assessed and how they align with learning outcomes. The system further helps to assess and ensure that there is a high level of consistency across all sections of the same course.

The objective of this paper is to present the PCAS to the broader community as one of the University of Alberta's implemented systems for continuous improvement and engage others in information and process sharing.

\section{POST COURSE ASSESSMENT SYSTEM}

\subsection{Assessment process}

Near the end of each term, instructors teaching courses receive an automated reminder that their post course assessment (PCA) forms need to be filled out. As the Faculty of Engineering believes in quality course offerings at every level, PCA forms are used for both undergraduate and graduate courses to ensure the highest quality control for all levels of teaching. Associate Chairs (Graduate programs) are responsible for graduate courses. The intent of the reminder is to ensure that instructors begin reflecting on their course, what worked, what did not, what new practices or approaches were attempted, as well as their students' performance in different aspects of the course, abilities, and preparation. Instructors are required to complete the PCA soon after the end of the examination period; it is our experience that when instructors delay answering the PCA, their recollection of their course is affected by other day to day activities and responsibilities. The system allows instructors access to view their previous PCA forms for each course they teach; this availability is useful for facilitating course preparation and adapting course content or delivery to respond to an instructor's own past comments. However, it should be noted that this could led to complacency, which will need to be identified

\subsection{System elements}

The PCAS has six elements for instructors to complete:

1. Student preparation

2. Learning outcomes

3. Course content

4. Learning strategies

5. Graduate attributes

6. Other comments
Herein, an example of a course taught by one of the authors will be used to illustrate use of the system. The course is MecE 415 Busting Myths with Analysis, a program (technical) elective developed loosely based on the Discovery channels' Mythbusters TV show. The overarching objective of this course are to apply 3 years of undergraduate training in Mechanical Engineering to unconventional multiphysics problems. Core courses taken by undergraduate students provide an excellent knowledge base; however, it can be a major leap to apply this knowledge to more complex problems. Higher order thinking skill such as synthesis [10] is a major part of most technical engineering work, and so it is important for our students to develop proficiency in this regard. In previous years, this course typically had the instructor go through 25 "myths" over the course of the term and included assignments, a small capstone project, a midterm, and a final examination. However, in winter 2017, the instructor changed the delivery and course assessments, and included many more elements to promote student engagement (online forums, group debates, peer assessments).

The PCAS is an effective means of informing Associate Chairs (undergraduate) and program planning committees of the successes or challenges of course changes, while also maintaining a formal record. It should be noted that in the $\mathrm{U}$ of A Faculty of Engineering, certain course changes, such as the removal of midterm and final examinations from a course, require a formal process of approval, and cannot simply be done at the discretion of the course instructor. In this paper, we present the instructor's assessment of the changes made to MecE 415.

Student preparation: in this section, instructors are asked to answer four questions:

1. In terms of knowledge, how well are students prepared for your course?

2. What are particular deficiencies in the knowledge of the students (if applicable)? Can you suggest a corrective action?

3. In terms of other skills (communication, time management, teamwork, etc.), how well are students prepared for your course?

4. What are particular deficiencies in student skills (if applicable)? Can you suggest a corrective action?

Questions 1 and 3 above receive a ranking from 1 to 5, where 1=low/poor, 3=acceptable, and 5=high/excellent. Questions 2 and 4 are free form text answer. When identifying weaknesses, it is critical that instructors detail the concerns and suggestions such that Associate Chairs and APC have context surrounding the issue allowing them to determine if actions need be taken or if this the issue is simply internal to the course and instructor. In the latter case, the PCAS allows the instructor to reflect on the issue and develop strategies, independently or with mentors/colleagues, to address them. In Fig.1, example 
responses to questions 1 to 4 for MecE 415 are presented. The comments reflect the instructor's belief that students lack confidence in their abilities, but that there is no knowledge deficiency; however, they do note a lack of soft skills. This was originally identified in the previous course offering's assessment. Here the changes made to the course in response to the previous year's findings are listed and discussed.

Learning outcomes: Our APCs, or Associate chairs, have worked with course instructors and program directors to establish a list of core program and course learning outcomes that must be a part of the course, regardless of instructor. These core learning outcomes are meant to ensure consistency between course offerings. Once set, an individual instructor cannot change the core outcomes; they can, however, add a few of their choosing that fit within the course calendar description and general course objectives. In this section, instructors are asked to reflect on how well, on a scale of 1 to 5, the learning outcomes were achieved by the class. As well, they are asked to evaluate on the same scale how appropriate each outcome is in the context of the course; this assessment creates a direct feedback loop that can be used to fine-tune the learning outcomes of the course within the context of the overall program. Fig. 2 illustrates instructor responses for MecE 415. Here we see that each learning outcome is identified in the right-most column as being fully appropriate for the course; while, the level of achievement falling as 4 or 5 indicating very good level of achievement.

Course content: This section simply asks instructors "If any, what suggestions do you have for changes to the content of the course?" This is first a Y/N question which opens a free form box if " $Y$ " is selected. Here, instructors are encouraged to consider content changes that may improve the course. For MecE 415, the instructor focused their answer on course delivery and student feedback:

"The course content is largely driven by students selecting the myths they want me to do, which make the offering unique every year. However, as the course is based on the Mythbusters show, they would like to see real explosions. This will never happen but adding a more experiential aspect to the course would be beneficial. This should be explored."

Learning strategies: The Faculty encourages instructors to consider different course delivery models, such as blended and active learning, as there is strong pedagogical evidence that such methods can lead to better learning for the student [11]. Through the PCAS, instructors can again reflect on delivery method opportunities and challenges. Our faculty evaluation report has a section about teaching initiatives; the PCAS can be the first point to developing such initiatives. We believe that by encouraging instructors to inform us of their efforts or thoughts on different course delivery methods through the PCAS, faculty members will see the value the Faculty places in teaching and may consider changing their approach and/or consider getting support in changing their delivery.

Two Y/N questions, with free form text boxes opening in the affirmative, are posed here:

- Can you identify opportunities for increasing active learning in this course?

- $\quad$ Are there good opportunities for blended learning and alternate delivery?

MecE 415 responses to learning strategies are provided in Fig. 3. 


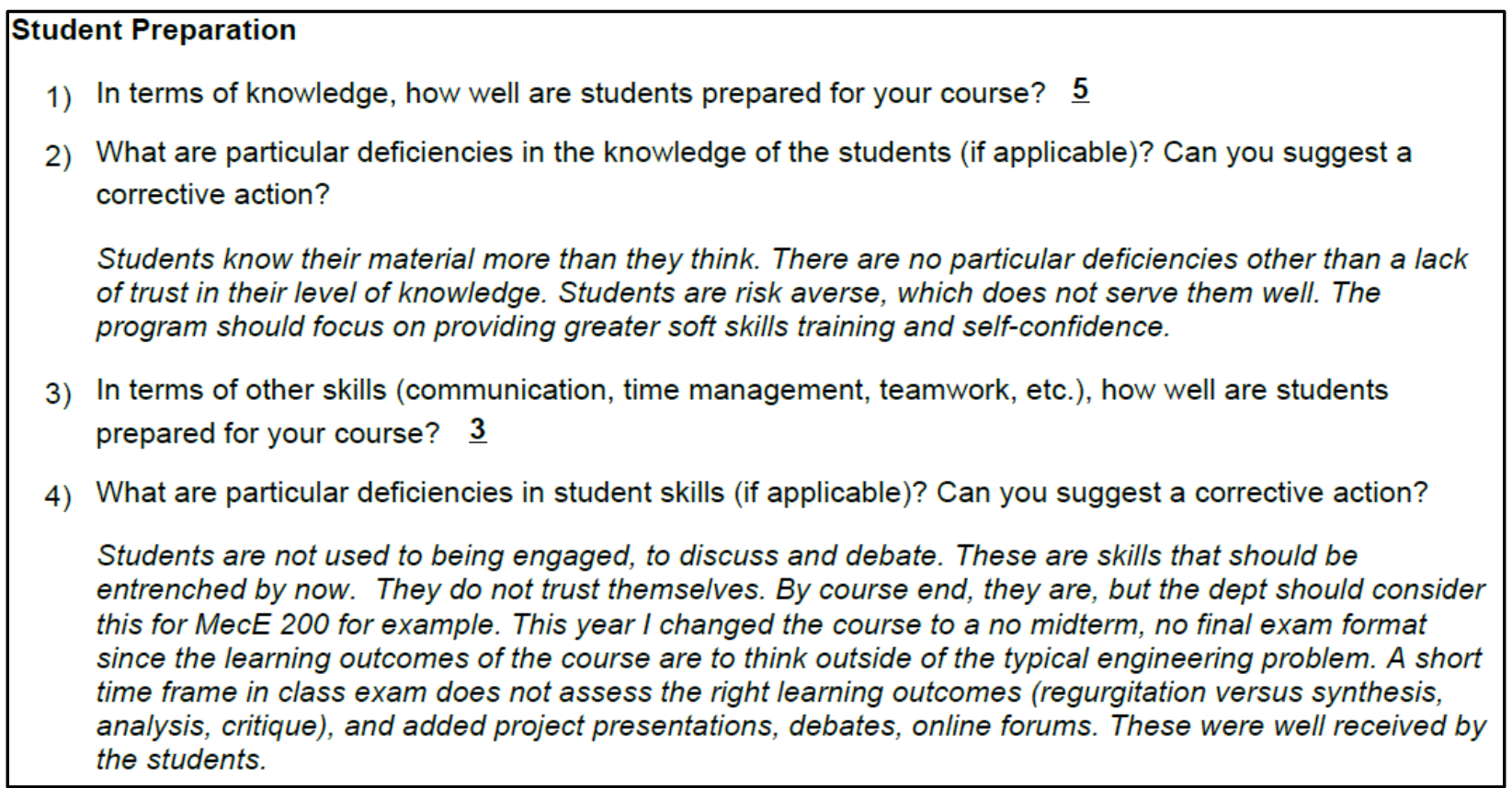

Fig. 1. Student preparation responses.

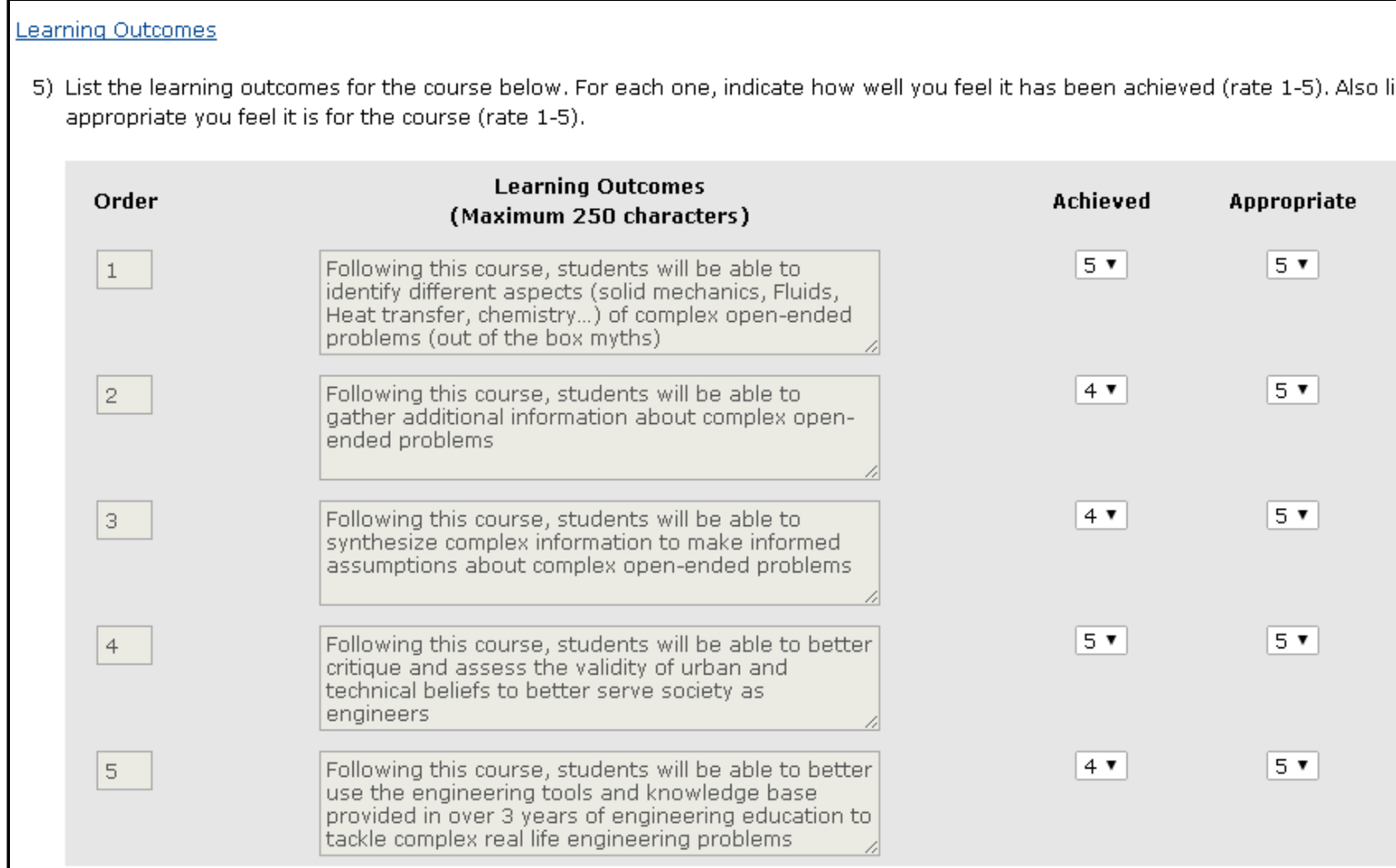

Fig. 2. Learning outcomes responses. 


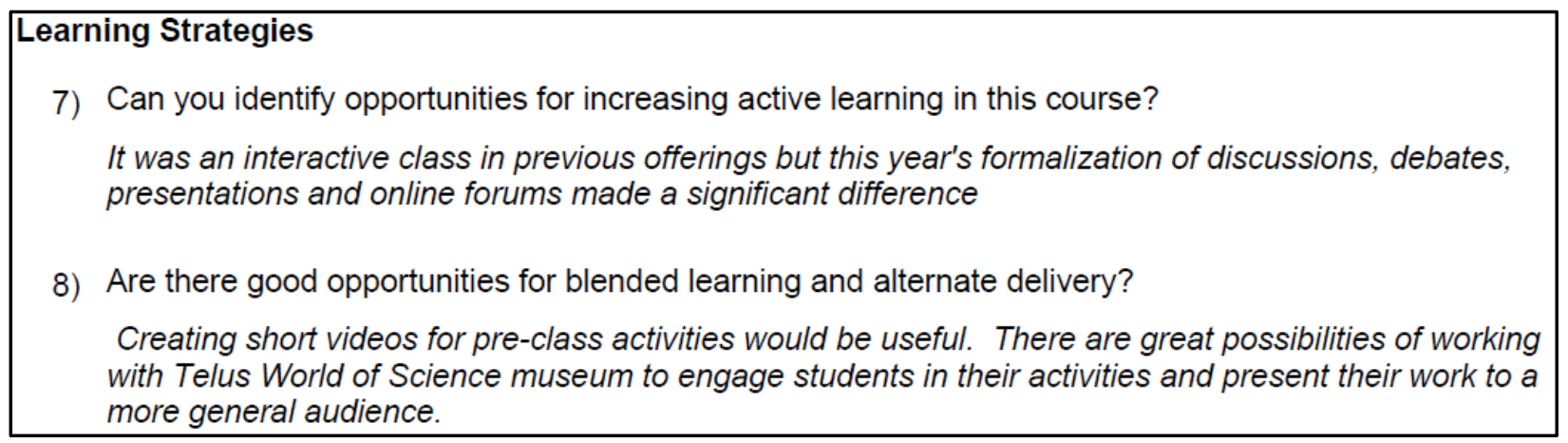

Fig. 3. Learning strategies responses.

Graduate attributes: This section serves multiple purposes. For undergraduate $(1 \mathrm{xx}$ to $4 \mathrm{xx})$ or joint undergraduate/graduate $(5 \mathrm{xx})$ courses it defines and identifies to instructors the current set of CEAB graduate attributes associated with their course, along with the level to which the each graduate attribute is developed in the course, using the CEAB levels of introductory (I), developing (D), and advanced (A). The PCAS also allows instructors the opportunity to identify a maximum of three graduate attributes not already listed that could be associated with the course. CEAB requires that programs continuously assess where, and at which level, graduate attributes are being developed; this aspect of the PCAS serves as direct feedback from the instructors about what is occurring in their course.

For example, MecE 415 is currently associated with the graduate attributes shown in Table 1 . The instructor indicated that in terms of the knowledge base graduate attribute, the level should be advanced (A) instead of developing (D) as currently set by APC; and that the Communication skills and Lifelong learning graduate attributes should be considered at a developing level for this course.

Table 1: Graduate attributes developed in MecE 415.

\begin{tabular}{|l|c|}
\hline \multicolumn{1}{|c|}{ Graduate Attribute } & Level \\
\hline A knowledge base for engineering & $\mathrm{D}$ \\
\hline Problem analysis & $\mathrm{A}$ \\
\hline Use of engineering tools & $\mathrm{I}$ \\
\hline $\begin{array}{l}\text { Impact of engineering on society and the } \\
\text { environment }\end{array}$ & $\mathrm{I}$ \\
\hline
\end{tabular}

Other comments: This is the catch all section that asks instructors: "Are there other issues that the department should be aware of?" Here, again, answering in the affirmative opens a free form text box in which instructors can provide any additional information, positive or negative on the course they just taught. In the case of MecE 415, the instructor, who is a member of the Faculty APC provides information on the current course and the changes to curriculum that are underway.

"Communication and writing must be a greater part of our program to ensure that our students are better prepared for the next stage of their careers. A single 4th year elective taken by a small number of our students should not be the only (or one of the only) opportunities for them to improve communication, rhetoric and argumentative skills, as well as taking risks in their projects. I am glad to hear that there are curriculum changes coming in terms of ENGL 199 and first year design-process course."

This type of feedback was a driver to some of the continuing improvement actions being taken by APC.

\subsection{Internal review process and action triggers}

It is important that any form instructors are required to fill out is be used effectively and that feedback is provided instructors from those in charge of reviewing the submissions. Only a select few members of the Faculty have access to the PCAS submissions, namely: Associate Chairs for the undergraduate and graduate programs, Associate Dean and Director of Programs and Planning (ex-officio members of program and Faculty APC committees, responsible for curriculum changes); those responsible for working with instructors to ensure that our programs and courses deliver what they are supposed to.

As it would be overly onerous to manually review each and every PCA form, the system was developed with triggers that alert Associate Chairs of elements in specific courses that were identified by instructors as problematic. Where in the previous sections it was identified that ratings could be provided between 1 and 5 , any rating that falls below 3 , or acceptable, is flagged as requiring action.

If a rating is set at 2 or lower, the database alerts the program lead or delegate (Associate Chair Undergraduate Program) to investigate the concern by conducting a review of the form and engaging in a discussion with the instructor 
to determine the true severity of the issue and explore possible next steps. These discussions should be documented, even if the concern is determined to be a nonissue. Instructors are encouraged to improve or develop new initiatives to improve the curriculum; it is encouraged that the department be aware and support and document such initiatives. Although there is no alert to indicate to program administrators if a course is going very well, it is important to consider in the future a more formal means to have well managed courses be models to assist improvements in the courses and programs as well.

As a result of the expected year-to-year variability from sample size, changes in the instructors making the assessments and the differences in the assessments used, and minor fluctuations in the abilities of the student body, no changes to curriculum or program will be considered based on a single data point. If a concern is noted, the course is flagged by the Associate Chair and future data will be investigated. When appropriate, Associate Chairs will consult those instructors teaching prerequisites to the flagged course to determine if course plans and learning outcomes follow the calendar description and are met.

If concerns continue over 3 consecutive course offerings, or 3 out of 5 consecutive course offerings the Associate Chair will bring the concern to the department APC for review, and propose, if required, a plan (curriculum change, changing prerequisites, etc.) to remedy the situation. Any proposed plans should be supported by the effected course instructors. It is always recommended that Department APC chair discuss curriculum concerns with the chair of Faculty APC and the Department Chair.

If changes, beyond small course adjustments, are made to courses or program and approved by Department APC, the proposals must be ratified, in order by, Department Council of the program, Faculty APC and Executive Coordinating Committee, prior to confirmation by University Governance.

\section{Discussion}

The aim of this paper was to introduce the University of Alberta, Faculty of Engineering's tool and approach to closing a feedback loop between program administrators and instructors and to elaborate upon how this tool can be used as a trigger mechanism for program changes. The PCAS was developed as an automated tool that allows instructors to provide feedback about a range of course related issues, enabling program administrators to gain insight on how courses are going and a means by which to trigger program-changing actions. Further, and most importantly, it allows instructors a voice in the program as key stakeholders, regardless of whether or not they are members of the curriculum committee.

The PCAS has certainly helped a number of instructors adapt and modify their courses as was the case for MecE
415 by providing the instructor an opportunity to reflect on their course.

More importantly, the PCAS has been very beneficial for our programs as it allowed APC to identify critical areas requiring immediate attention. In the first year of results gathered by the PCAS, it was identified that many of the learning outcomes for courses in our programs were poorly written, misaligned with curriculum expectations, or simply a list of items tackled in classes. The Faculty of Engineering dedicated resources, Associate Chairs dedicated timeless hours, and the $U$ of A's Centre for Teaching and Learning was consulted to provide training to our faculty members through a series of workshops and individualized help to complete the learning outcomes of all engineering courses. Furthermore, the workshops were expanded to external faculties offering out-of-Faculty service, program and complementary studies courses, thus improving the defined course learning outcomes beyond engineering.

A second outcome arising from the PCAS was a general consensus that our students were not exhibiting the level of writing and communication skills expected of our graduates. It was identified that students could take their required English course at any time during their degree, leading to inconsistency in student preparedness, and limiting instructors' ability to follow a set series of writing and communication conventions. Furthermore, the primary English course taken by engineering students did not meet the Faculty of Engineering's expectations in terms of content. The course content has since been redeveloped in collaboration with the English and Film Studies department to better meet our expectations. The course will be made mandatory and placed in students' first year of study, ensuring that students receive early in their program the skills required to succeed. These changes will also allow programs to set uniform, high level writing and presentation standards.

The implementation of the PCAS was not without initial controversy and resistance. Many faculty members believed that the forms would be used for faculty evaluation. It was a common thought that identifying challenges in courses would be blamed on the instructor and would reflect in their yearly evaluation. As in most such cases and in implementing new program-based tools, a reinforcement of facts and culture change were required.

A second challenge was to address the concern that the information provided had not fed into feedback to instructors. In identifying the critical issue around learning outcomes, it was true that course by course challenges were not quickly addressed and the feedback loop not closed. The importance of addressing program learning outcomes overshadowed most other course-by-course issues; however, through accreditation based workshops delivered by the Faculty the situation was addressed, allowing the focus to shift to individual course concerns moving forward. The lack of feedback to instructors that occurred 
in the early stages of implementation must be avoided at all cost for the process to work and to continue to have instructor buy-in.

\section{CONCLUSIONS}

This paper presents the University of Alberta, Faculty of Engineering post course assessment system. To date, the system has been successful in identifying course and program-based issues, which have led to positive changes as an integral part of our continuous improvement process. The system has proved to be an invaluable way to obtain instructor feedback on courses and programs. It provides a means to inform program administrators of challenges and successes and allows for informed discussions with instructors. Finally, the PCAS offers a much-needed formal and automated means of triggering actions for course or program reviews.

\section{Acknowledgements}

The authors acknowledge the database development work of Grace Jiang and feedback from Dr. Arvind Rajendran.

\section{References}

[1] Christopher R. Dennison, Robert Butz, R. Shawn Fuhrer, and Jason P. Carey, "Comparison of student evaluation of teaching results when stratified by protocol, course content, and course structure," International Journal of Engineering Education, vol. 31, no. 6, pp. 1476-1490, 2015.

[2] Canadian Engineering Accreditation Board (CEAB), 2016 Accreditation Criteria and Procedures. Revised February 2017, 125 pp. Available as of April 25, 2017 from https://engineerscanada.ca/sites/default/files/accreditationcriteria-procedures-2016-final.pdf

[3] Jeff Jalkio, and Arnold Weimerskitch, "Using the Deming cycle for continuous improvement in engineering education," in Proc. ASEE Annual Conference and Exposition, ASEE, (Pittsburgh, Pennsylvania; 22-25 June 2008), 11 pp., 2008.
[4] Jay Goldman, and David A. Conner, "Development of assessment instruments," in Proc. ASEE Annual Conference, ASEE, (Charlotte, North Carolina; 20-23 June 1999), 7 pp., 1999.

[5] Said M. Easa, "Framework and guidelines for graduate attribute assessment in engineering education," Canadian Journal of Civil Engineering, vol. 40, no. 6, pp. 547-556, 2013.

[6] Donald L. McEachron, Elisabeth Papazoglou, Fred Allen, and Mustafa Sualp, "Work in progress - An evidence-based intervention system to enhance engineering education," in Proc. Frontiers in Education Conf., IEEE, (Washington, DC; 27-30 October 2010), 2 pp. 2010.

[7] Shahryar Darayan, David Olowokere, and Xuemin Chen, "Utilizing program outcomes in the modification of engineering technology curriculum," in Proc. of the 12th International Conference on Engineering, Science, Construction, and Operations in Challenging Environments - Earth and Space, , Gangbing Song (ed.), Ramesh B. Malla (ed.), (Honolulu, Hawaii; 14-17 March 2010), 10 pp. 2010.

[8] Stafani A. Bjorklund, and Carol L. Colbeck, "View from the top: leaders' perspectives on how to involve faculty in improving engineering education," in Proc. Frontiers in Education Conf., IEEE, (San Juan, Puerto Rico; 10-14 November 1999), 5 pp., 1999.

[9] William Howard, and Joseph Musto, "View from the top: leaders' perspectives on how to involve faculty in improving engineering education,” in Proc. ASEE Annual Conference and Exposition, ASEE, (Chicago, Illinois; 18-21 June 2006), 7 pp., 2006.

[10] Lorin W. Anderson, David R. Krathwohl, Peter W. Airasian, Kathleen A. Cruikshank, Richard E. Mayer, Paul R. Pintrich, James Raths, and Merlin C. Wittrock, A Taxonomy for Learning, Teaching, and Assessing: A Revision of Bloom's Taxonomy of Educational Objectives. Boston, MA: Pearson Education Group, 2001, 336 pp. \{ISBN: 978-0-801-319037\}

[11] Richard M. Felder, and Rebecca Brent, Teaching and Learning STEM: A Practical Guide. San Francisco, CA: Jossey-Bass, 2016, 336 pp. \{ISBN: 978-1-118-92581-2\} 